\title{
O Ensino de Geologia para as Ciências Biológicas
}

\author{
Teaching Geology for Biological Sciences
}

\author{
Erich de Freitas Mariano ${ }^{1}$
}

\begin{abstract}
RESUMO
Em pleno Século XXI, a regra educacional consiste em uma prática docente baseada na memorização e mecanização curricular. Nos currículos de formação dos professores em ciências biológicas encontramos termos que remetem a processos trans e interdisciplinares. O que nos perguntamos é se realmente esses processos estão além de conceitos escritos e esquecidos em seus respectivos projetos pedagógicos. Nesse aspecto trago a disciplina de Geologia dentro das Ciências Biológicas como um exemplo de integração de conhecimentos por ter em seu corpo teórico informações que, quando integralizadas à formação biológica, nos ajudam a compreender o homem como agente responsável e atuante no planeta. A Terra é um sistema complexo, no qual as rochas, a água e a vida interagem. Entender como funciona o planeta e como suas diferentes dinâmicas interagem entre si e com as dinâmicas biológicas, incluindo o ser humano, proporciona uma compreensão de que fazemos parte de um todo. Compreender suas dinâmicas e as relações com as dinâmicas biológicas é um ponto chave para a formação de cidadãos "geologicamente esclarecidos" e que sejam agentes ativos na comunidade por meio do conhecimento científico construído.
\end{abstract}

Palavras-chave: Interdisciplinaridade; Ciências da Terra; Processos Geológicos;

\begin{abstract}
In the 21 st century, the educational rule consists of a teaching practice based on curricular memorization and mechanization. In the biological sciences teacher education, we find terms that refer to trans and interdisciplinary processes. What we ask ourselves is whether these processes really are beyond written and forgotten concepts in their respective pedagogical projects. In this aspect, I bring the discipline of Geology within Biological Sciences as an example of knowledge integration as it has in its theoretical body information that, when integrated into biological formation, help us to understand man as a responsible and active agent on the planet. The Earth is a complex system in which rocks, water and life interact. Understanding how the planet works and how its different dynamics interact with each other and with biological dynamics, including humans, provides an understanding that we are part of a whole. Understanding their dynamics and relationships with biological dynamics is a key point for the formation of "geologically enlightened" citizens who are active agents in the community through constructed scientific knowledge.
\end{abstract}

Keywords: Interdisciplinarity; Earth Sciences; Geological Processes;

${ }^{1}$ Laboratório de Pesquisa em Ensino, Zoologia e Conservação - LAPEZC/UACB. Universidade Federal de Campina Grande. *E-mail: efmariano.ufcg@gmail.com 


\section{INTRODUÇÃO}

O trabalho interdisciplinar e transdisciplinar é uma das práticas docentes mais importantes e, provavelmente, uma das mais difíceis de serem praticadas. O processo de integração de conhecimentos proporciona uma aprendizagem significativa, trazendo um ensino que faz sentido para os envolvidos no processo de construção (professores e alunos). Essa ideia segue o proposto por David Ausubel (1968) e é reforçada pelas ideias de desenvolvimento cognitivo (Piaget, 2011) e sociointeracionistas (Vygotsky, 1998).

Infelizmente, em pleno Século XXI, a regra educacional consiste em uma prática docente baseada na memorização e mecanização curricular. É de fundamental importância que o educador tenha em mente que o conhecimento cognitivo precisa estar engrenado com todos os aspectos do indivíduo e do meio no qual ele vive (Morin, 1996). É preciso associar o simples ao complexo e desta forma transpassar a informação recebida por segmentos cognitivos, éticos e existenciais e assim transformá-la em conhecimento.

As Ciências da Terra sempre foram fundamentais na história científica da humanidade, e hoje elas compreendem campos que nos ajudam a resolver inúmeros problemas sociais. Dispor de ferramentas que abordam as alterações da Terra suas consequências é a base para a tomada de decisão acerca da sustentabilidade (UNESCO, 2008) e é consenso na comunidade científica e de educadores que o cidadão deve compreender o funcionamento do nosso planeta e com isso ter ferramentas cognitivas para a tomada decisões no uso dos recursos (Bonito \& Morgado, 2017).

Nos currículos de formação dos professores em ciências biológicas encontramos sempre termos que remetem a esses processos trans e interdisciplinares. O que nos perguntamos é se realmente esses processos estão além de termos escritos e esquecidos em seus respectivos projetos pedagógicos e são realmente implementados. Nesse aspecto trago a disciplina de Geologia dentro das Ciências Biológicas como um exemplo de integração de conhecimentos por ter em seu corpo teórico informações que, quando integralizadas à formação biológica, nos ajudam a compreender o homem como agente responsável e atuante no planeta. 


\section{DESENVOLVIMENTO}

\section{Por que aprender Geologia?}

O objetivo da geologia é estudar os componentes minerais da Terra, verificando sua estrutura e composição e inferindo a partir dessas análises os processos envolvidos na sua origem e suas transformações ao longo do tempo. Em sua essência, a geologia envolve os conhecimentos e aplicações de outros ramos da ciência, como a física, química, matemática, astronomia e, claro, a biologia. Desta forma entendemos que ela é uma ciência que vai além do estudo das rochas. A partir de seus conhecimentos podemos não apenas entender como funciona nosso planeta, mas também como melhor aproveitar seus recursos minerais, como viver em ambientes que estão suscetíveis a eventos sísmicos, como podemos enriquecer nossos cultivos, como funcionam outros planetas e etc. Nesse processo integrativo do conhecimento podemos moldar a base para um melhor uso de nosso ambiente.

Essa visão integradora permite ver que o homem é um agente bio-geológico, ou seja, encontra-se no centro dos processos de transformação ambiental ao ponto de as novas formações geológicas e pedológicas estarem fortemente influenciadas por suas ações (Silva \& Hornik, 2011). Esse aspecto por si só já justifica termos um melhor entendimento das dinâmicas geológicas.

No meio acadêmico-científico, entender essas características integrativas supracitadas proporciona meios para compreender melhor as dinâmicas da história da Terra, incluído não apenas os aspectos naturais mas também referentes às dinâmicas de desenvolvimento econômico, social e tecnológico. Com isso proporcionamos uma ciência realmente crítica e prática, que permite reflexões relativas a grandes temas tais como mudanças climáticas, transgenia, sustentabilidade energética, dentre outros (Carrijo et al. 2010).

Na história da geologia no Brasil temos pontos marcantes que trouxeram para o final do século XIX e início do Século XX um incremento na construção do conhecimento geológico nacional e sua divulgação nos periódicos científicos.

Cordani et al. (2018) nos conta que apesar de termos a Escola de Sagres, um dos principais centros de estudos de ciências da Terra do Século XVI, participando do nascimento do Brasil não tivemos estudos geocientíficos relevantes. Nesse período ações extrativistas foram o centro das atividades geológicas na colônia tendo o Ciclo do Ouro no início do Século XVIII seu grande marco. Com a decadência das atividades 
mineradoras, especialistas formados em Portugal voltam ao Brasil com o objetivo de revitalizar e ampliar essa atividade e com isso surgem as primeiras publicações técnicocientíficas relacionadas. Não apenas as publicações surgem, mas também é criado, em 1780, o Imperial Observatório Nacional, primeira instituição brasileira a realizar estudos geofísicos.

A chegada da corte no país, no início do Século XIX, abrem-se as portas para estudos naturalistas e destaca-se entre os estudos geológicos a Pluto Brasiliensis (Riqueza do Brasil) de Wilhelm Ludwig von Eschwege e publicado em 1833, considerada o primeiro trabalho científico sobre a geologia do Brasil. Dom Pedro II, já imperador do Brasil, investiu em vários estudos relacionados às ciências da terra, publicando ele mesmo relatos sobre tremores de terra em território brasileiro e em 1875 criou a Comissão Geológica do Império.

Na segunda metade do Século XIX, Orville Adalbert Derby, foi um personagem fundamental para a consolidação dos estudos mineralógicos e paleontológicos do país. Foi ele quem organizou as coleções de mineralogia e paleontologia da Comissão Geológica do Império e devido a sua enorme contribuição científica é considerado o pai da geologia no Brasil.

Ainda no fim do século XIX as primeiras instituições de ensino de geologia surgem e os primeiros geólogos formados no país surgem dando início a "era moderna" da geologia. Atualmente o Brasil conta com 47 instituições de ensino superior que ofertam cursos de graduação nas Ciências da Terra, dentre eles 33 fornecem cursos de Geologia (Cordani et al., 2018). As duas grandes guerras do Século XX, o desenvolvimento das navegações marítimas comerciais, da exploração de recursos minerais e do fomento à atividade industrial a partir dos investimentos do governo federal nos anos de 1950 tornaram o conhecimento geológico parte do cotidiano do povo brasileiro.

Hoje aplicamos o conhecimento acumulado em nossos dias sem nos darmos conta disso. Desde a energia gasta em nossas casas e automóveis, ao nosso jardim bem decorado e vivo até o valor do dólar e o estado econômico do país sofrem influência direta da geologia.

Apesar da sua significância, os conhecimentos relacionados às geociências são pouco difundidos na educação básica, ao ponto de $83 \%$ dos estudantes de ensino médio do estado do Rio de Janeiro não saberem o que é a Paleontologia (Duarte et al. 2016). 
Dentre as causas elencadas para esse resultado é a pouca ênfase dos conteúdos relacionados nos currículos da educação básica e como consequência uma carência dos temas nos livros didáticos. Associado a isso encontra-se a relativa baixa carga horária de disciplinas de geologia e paleontologia nos cursos de formação de professores, pouca cobrança dos temas em processos seletivos, investimento limitado em projetos de extensão abordando as geociências e a má receptividade nos diversos ambientes educacionais devido a influências religiosas (ver Duarte et al. 2019).

\section{Geologia na Biologia: Dinâmicas que se sobrepõe}

A importância da geologia citada anteriormente aponta diversos níveis de interação e de relevância didática e científica com a biologia. Porém, para que esse processo de construção de conhecimento interdisciplinar ocorra é preciso promover a contextualização entre os conteúdos. É fundamental uma análise e adequação dos currículos para que os temas clássicos e os inovadores possam ser incorporados às atividades formativas (Carrijo et al., 2010).

Um primeiro entendimento de sobreposição entre as disciplinas de geologia e biologia está na abordagem histórica na qual essas duas ciências operam. Ambas visam explicar eventos passados a partir dos efeitos, ou produtos, gerados por esses eventos. Desta forma, modelos explicativos do passado são gerados a partir de aspectos e conhecimentos sobre o presente (Silva \& Hornik, 2011). Podemos identificar fenômenos climáticos e/ou ecológicos a partir da análise de diferentes camadas de rochas e da verificação das marcas físicas, químicas ou biológicas que esses eventos deixaram. Da mesma forma, podemos reconstruir linhagens ancestrais a partir da análise do compartilhamento de caracteres das espécies viventes.

Essa abordagem histórica no reconhecimento de linhagens e ambientes ancestrais se faz "indispensável para a explicação de todos os aspectos do mundo vivo... em outras palavras... todos os aspectos que lidam com a evolução" (Mayr, 2005). Pensar em eventos do passado como exclusivamente biológicos é inviável para sua total compreensão, o cenário mais realista só surge quando incluímos o tempo geológico nessas explicações (Silva \& Hornik, 2011).

Se partirmos para uma abordagem mais mecanicista, na busca de entender os processos envolvidos nas dinâmicas geológicas e biológicas, ainda nos deparamos com eventos históricos e a biogeografia é um grande exemplo. Entender a dinâmica de 
funcionamento e de ciclagem de rochas e todo o processo de tectônica de placas é a base para explicarmos eventos vicariantes que permitiram os padrões de distribuição das espécies que encontramos hoje. E associado aos padrões de movimentação continental estão as mudanças climáticas que levaram ao surgimento e desaparecimento de eras glaciais, regressão e transgressões marítimas, expansão e retrações florestais. Compreender o ciclo das rochas nos ajuda a compreender como os habitats são formados.

Se falamos em formação de habitats, podemos diminuir essa visão macroscópica, que observa as grandes transformações ao longo do tempo geológico, e perceber habitats sendo transformados hoje, em escalas menores. Processos pedológicos apresentam relações intrínsecas entre dinâmicas geológicas e biológicas. A formação dos solos é afetada por eventos de erosão das rochas associadas a ação biológica, as quais são influenciadas pelos aspectos geofísicos locais, tais como temperatura, umidade, radiação, relevo, dentre outros.

A influência biológica nas dinâmicas geológicas é um fator importante para sua própria manutenção e o homem, como agente bio-geológico, também se encontra envolvido nesse sistema. Não apenas as mudanças na paisagem proporcionada pela ação antropogênica, mas também a influência que os ciclos biogeoquímicos exercem sobre nossas vidas, como o ciclo de água, carbono e nitrogênio, são questões que devem ser levadas em conta no processo interdisciplinar de ligação entre geologia e biologia.

\section{CONSIDERAÇÕES FINAIS}

A vida evolui ao longo tempo e interage com a Terra, modificando-a e sendo modificada por ela. Os fósseis e as camadas geológicas são evidências dessas interações e com eles podemos reconstruir paisagens há muito perdidas. A tectônica de placas permite uma conexão, não apenas filosófica, mas também física, entre porções hoje distantes no planeta e reforça o aspecto integrado de nossa existência.

Todas as dinâmicas e processos geológicos modificam a superfície da Terra e a humanidade, que depende de seus recursos, precisa dominá-la (no sentido de compreendê-la) para um melhor e mais sustentável aproveitamento.

Por fim, a Terra é um sistema complexo, no qual as rochas, a água e a vida interagem. Entender como funciona o planeta e como suas diferentes dinâmicas interagem entre si e com as dinâmicas biológicas, incluindo o ser humano, proporciona uma compreensão de que fazemos parte de um todo. Compreender suas dinâmicas e as 
relações com as dinâmicas biológicas é um ponto chave para a formação de cidadãos "geologicamente esclarecidos" e que sejam agentes ativos na comunidade por meio do conhecimento científico construído.

\section{REFERÊNCIAS}

Ausubel, D. P. Psicologia Educacional. Rio de Janeiro: Interamericana, 1968.

Bonito, J \& Morgado, M. As Ciências da Terra na disciplina de Ciências Naturais do ensino básico em Portugal. Terrae Didatica, v. 13, n. 3, p. 258-270, 2017.

Carrijo, R; A Candeiro, C R. O Ensino de Geologia, Paleontologia e Química no Centro Universitário do Planalto de Araxá (Uniaraxá). A importância das Geociências. Revista de Biologia e Ciências da Terra, Campina Grande, v. 10, n. 1, p. 62-66, 2010.

Cordani, U. G; Ernesto, M.; Dias, M. A. F. S.; Saraiva, E. S. B. G.; Alkmim, F. F.; Mendonça, C. A.; Albrecht, R. Ensino de Geociências na universidade. Estudos Avançados, [S.L.], v. 32, n. 94, p. 309-330, dez. 2018.

Duarte, S. G. et al. Conhecimento prévio de paleontologia e geologia de ingressantes em cursos de Ciências Biológicas e G. Terrae Didatica, [S.L.], v. 15, p. 1-12, 10 set. 2019. Universidade Estadual de Campinas. http://dx.doi.org/10.20396/td.v15i0.8654529.

Mayr, E. Biologia, Ci^nncia Única: Reflexões sobre a autonomia de uma disciplina científica. São Paulo: Companhia das Letras, 2005.

Morin, E. O método III: o conhecimento do conhecimento. Portugal: Publicações Europa-America, 1996.

PIAGET, J. Seis estudos de Piaget. Rio de Janeiro: Forense Universitária, 2011.

Silva, F. K. M; Hornink, G. G. Quando a Biologia Encontra a Geologia: possibilidades interdisciplinares entre areas. Alexandria, Florianópolis, v. 4, n. 1, p. 117-132, maio 2011.

UNESCO. Declaración presentada en el Acto Mundial de Inauguración del Año Internacional del Planeta Tierra (AIPT). 2008. Disponível em:

http://yearofplanetearth.org/content/GLE/declaration/Declaration_Spanish.doc. Acesso em: 25 jun. 2021.

\section{Recebido em: 01/09/2021}

Aprovado em: 20/09/2021

Publicado em: 27/09/2021 